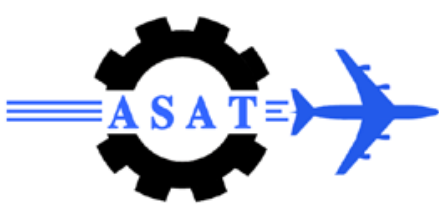

\title{
A Neural Predictive Control Scheme for Small Turbojet Engines
}

\author{
${\text { I.M. } \text { Atia }^{*} \text { and A.M. Bayoumy }}^{\dagger}$
}

\begin{abstract}
Artificial Neural Networks (NN) is a well-known tool among artificial intelligence techniques that are able to reproduce arbitrary nonlinear relationships existing between input and output variables. Model based Predictive Control (MPC), or simply predictive control, is a family of control schemes that uses a model from the plant as a predictor of the future plant outputs a nd he nce opt imizes the future $c$ ontrol i nputs for the m inimum future e rrors a nd minimum control energy. Among this family Generalized Predictive control (GPC) is one of the most famous.
\end{abstract}

In another part of this work [5],, a neural network representation is shown to be suitable for modeling a small gas turbine engine (SR-30). In the present pa per, this model is us ed in a model-based predictive $\mathrm{c}$ ontrol s cheme. The $\mathrm{r}$ esults of this $\mathrm{c}$ ontroller a re compared $\mathrm{w}$ ith a classical P roportional-Integral-Derivative ( PID) $\mathrm{c}$ ontroller tune $\mathrm{d}$ offline $\mathrm{w}$ ith a $\mathrm{g}$ enetic optimization technique. Both are tested on the SR-30 turbojet engine model.

PID cont roller cann ot cope with model changes in the whole op erating range of the engine and therefore a predictive control scheme is then proposed as a solution to this problem. A neural $\mathrm{m}$ odel is us ed as a pr edictor for the calculation of G PC parameters. The nonl inear system free response is obtained by recursive future predictions while the dynamic response matrix is obtained by instantaneous linearization of the input /output relation.

The results illustrate the improvements in control performance that could be achieved with a neural predicative scheme compared to that of a classical PID controller.

Keywords: Small tur bojet e ngines, artificial int elligence, neural $\mathrm{n}$ etworks, predictive controller, PID, GPC.

\section{Nomenclature}

ARX AutoRegressive with eXternal input

$\mathrm{F} \quad$ Vector of predicted free response

$\mathrm{G} \quad$ system impulse response matrix

$\mathrm{G}_{\mathrm{f}} \quad$ Fuel flow rate $(\mathrm{kg} / \mathrm{s})$

$\mathrm{K}_{\mathrm{d}} \quad$ derivative gain

$\mathrm{K}_{\mathrm{i}}$

$\mathrm{K}_{\mathrm{p}}$, $\quad$ proportional gain, integral gain

$\mathrm{N} \quad$ Engine revolution speed,(rpm)

$\mathrm{N}_{1} \quad$ lower value of predicting horizon

$\mathrm{N}_{2} \quad$ Higher value of predicting horizon

NN Neural networks

\footnotetext{
*Egyptian Armed Forces, Egypt, Hema1080@yahoo.com

${ }^{\dagger}$ Egyptian Armed Forces, Egypt, ambayoumy@gmail.com
} 


$\begin{array}{ll}\text { NNGPC } & \text { Neural network generalized predictive controller } \\ \mathrm{N}_{\mathbf{u}} & \text { Control horizon } \\ \mathrm{PID} & \text { Proportional, integral and derivative controller } \\ \mathrm{T} & \text { Sampling time } \\ \mathrm{t}_{\mathrm{r}} & \text { Rise time } \\ \mathrm{t}_{\mathrm{s}} & \text { Settling time } \\ \hat{\mathbf{y}} & \text { Vector of predicted outputs for prediction horizon } \\ \tilde{\mathbf{u}} & \text { Vector of future control increments for the control horizon } \\ \mathbf{w} & \text { Vector of future references } \\ \lambda & \text { Weighting factor for control increments }\end{array}$

\section{Introduction}

Model $\mathrm{B}$ ased $\mathrm{P}$ redictive $\mathrm{C}$ ontrol ( $\mathrm{MBPC}$ ), or $\mathrm{s}$ imply $\mathrm{P}$ redictive $\mathrm{C}$ ontrol, i s a $\mathrm{f}$ amily of algorithms with common strategy. MBPC appeared in the decade of 1970s and had got a good reputation in the chemical industries and process control [1].

The ma in strategy of the MBPC is as follows, (Error! Reference source not found.): A model of $t$ he $c$ ontrolled s ystem i s us ed $t o$ pr edict $i$ ts be haviour i $n t$ he f uture. A know $n$ required reference trajectory is then given for certain prediction horizon. Then an optimisation algorithm is us ed to find the opt imum control s equence for c ertain num ber of steps in the future that minimise a certain cost function which includes future predicted errors and control increments. A receding horizon technique is then applied where only the first control signal of the optimum future control sequence is applied to the controlled system.

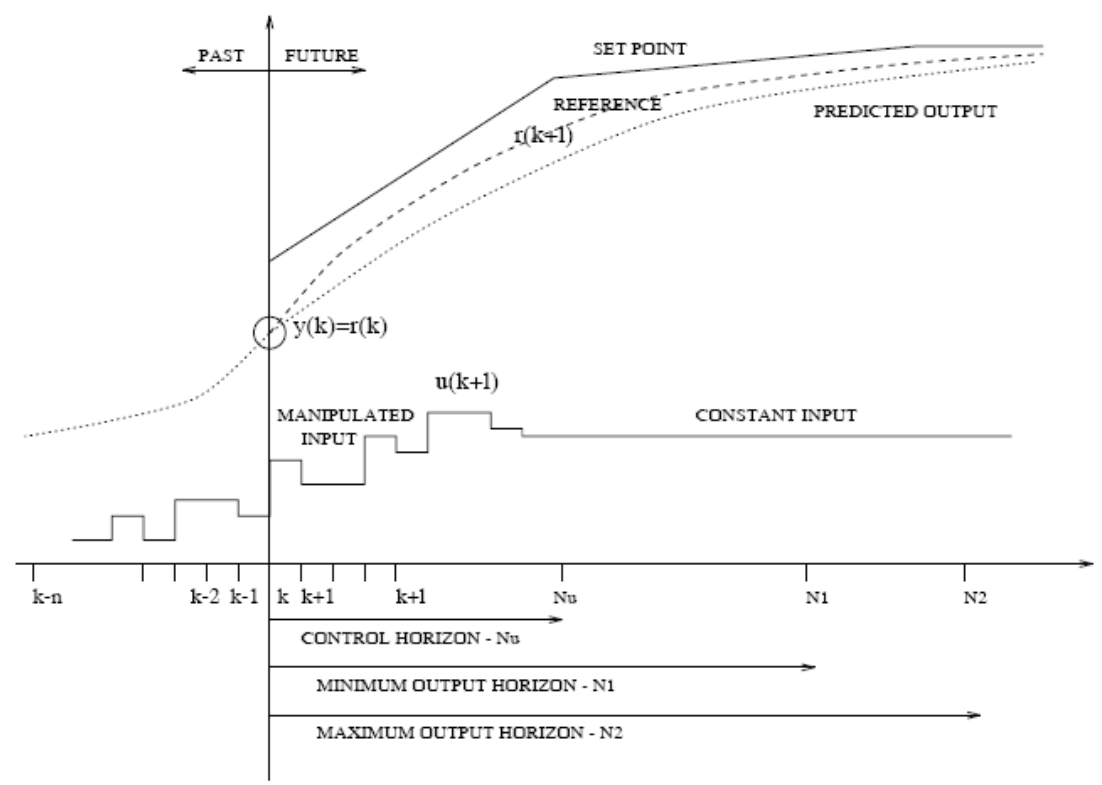

Fig. 1 Prediction strategy

Generalized Predictive Control (GPC) was developed by Clarke et al. in 1987 [2]. The GPC uses ideas from Generalized Minimum Variance (GMV) [3] and is perhaps one of the most popular methods at the moment.

Since the last three decades predictive control has shown to be successful in control industry. Generalized $\mathrm{P}$ redictive $\mathrm{C}$ ontrol ( GPC) $\mathrm{w}$ as one of $\mathrm{t}$ he $\mathrm{m}$ ost $\mathrm{f}$ amous 1 inear pr edictive algorithms. T he control 1 aw of $\mathrm{G} \mathrm{PC} c$ ontains $t$ wo parameters $t$ hat $d$ escribe $t$ he $s$ ystem dynamics: s ystem f ree $r$ esponse ( $f$ ) and system i mpulse $r$ esponse $m$ atrix $(G)$. Often these parameters a re c alculated from the di screte line ar mode 1. For nonl inear s ystems, either a 
nonlinear system model is instantaneously linearized or a nonlinear optimization is used. The validity of the linear model is the shortcoming of the first one and the possibility of non uniqueness of local minimum is that for the second. The neural network (NN) model is used as a predictor to calculate these parameters for GPC.

The nonl inear s ystem free $r$ esponse is obt ained instantaneously w hile d ynamic response is linearized e very $b$ atch of time. This method [4] is tested on a benchmark nonl inear model. Results a re c ompared with $t$ hat of ot her neural pr edictive $t$ echniques $f$ ound i $\mathrm{n}$ pr evious literature. Also, this method in[4] is applied and validated on a realistic multivariable aircraft model. The simulation results show that this method has some good advantages over others neural pr edictive $t$ echniques. In one $h$ and, the s ystem d ynamics pa rameters ar e cal culated more accurately directly from the nonlinear NN model. And in the other hand, the used linear GPC has a cost function with only on e global minimum. The method in [4], as a trade-off between nonl inear ne ural pr edictive c ontrol ( NPC) a nd i nstantaneous 1 inearization approximate ne ural 1 inear pr edictive control ( APC), is promising for control of nonl inear systems.

A. W atanabe et al [7] w orked on P ID and fuzzy logic algorithm in order to control S R-30 turbojet e ngine. They ob tained transfer function of the SR-30 by using frequency response method. They tested and simulated both closed loop controller PID and fuzzy logic controller. They developed their model with MATLAB environment and tested it by NI LabVIEW.

R. Andoga et al [8] discussed digital electronic control of a small turbojet engine. They stated that the main purpose of control of gas turbine was increasing its safety and efficiency. Their engine w as c ontrolled b y PIC 16 F84A m icrocontroller, which ma nipulating th e fuel flow valve.

M.Lichtsinder et al. [9] worked on de velopment of a simple real-time transient performance model $\mathrm{f}$ or AMT $\mathrm{j}$ et engine. $\mathrm{T}$ he fast $\mathrm{m}$ odel i s obt ained us ing $\mathrm{t}$ he Novel $\mathrm{G}$ eneralized Describing Function, proposed for investigation of nonlinear control systems. They presented the Novel Generalized Describing Function de finition and then di scusses the application of this technique for the development a fast turbine engine simulation suitable for control and real-time applications.

In another part of this work [5], a neural networks representation is shown to be suitable for modeling a s mall gas tu rbine e ngine (SR-30). In the pr esent w ork, this model is us ed in a model-based predictive control s cheme. This mode 1 is line arized at different en gine design points, this linearized model is used in design of a classical PID controller. The PID controller is $t$ uned of fline $w$ ith a genetic opt imization technique. B oth c ontrollers a re t ested on $t$ he SR-30 $t$ urbojet e ngine model a nd $\mathrm{c}$ omparison i $\mathrm{s} \mathrm{m}$ ade be tween $\mathrm{t}$ he $\mathrm{r}$ esults $\mathrm{f}$ rom $\mathrm{t}$ hese controllers with the same input.

\section{Turbojet Engine Controller Design}

For a gas-turbine engine, particularly for a jet engine, the speed $n$ control is one of the most important a spects ( even mos $t$ impor tant tha $n$ the en gine $t$ emperature control) and it is currently realized by some specific hydro-mechanical or electro-mechanical controllers.

The engine speed is the most important ope rating parameter, especially for the multi-spool engines, because it represents the parameter which assures the most accurate co-relation with the engine thrust amount, as well as with the engine fuel consumption; meanwhile, the speed 
$n$ offers an image about the dynamic load of the engine mobile parts (compressor blades and disks, turbine blades and disks, shafts), as well as an indirect image about the thermal charge of the engine hot parts (combustor, turbine(s), exhaust nozzle).

An a ircraft engine ope rates at various flight regimes, that means at various flight speed and flight a ltitudes, which means that the engine th rust va riation must follow the a ircraft flight dynamics $n$ ecessities, therefore the e ngine s peed (and thrust) mus t b e strictly c ontrolled, because of its important operating role.

The engine speed is one of the engine operating parameters, which is the easiest to measure, both for steady state regimes and for dynamical regimes. That fact represents an advantage and promotes the engine speed as the most important controlled engine parameter.

In this paper one has studied an engine speed controller with fuel flow rate a s a regulating parameter. The controller design was based on engine neural networks model.

\section{Discrete PID Based on Engine NN Model}

The discrete PID controller was used with the NN model of the SR-30 turbo jet engine. Now, the tuning of the PID is achieved by using genetic algorithm. The GA is carried out using a MATLAB bui lt-in $\mathrm{r}$ outine s o c alled S imulink R esponse $\mathrm{O}$ ptimization (SRO) T oolbox a $\mathrm{s}$ shown in Fig. 2. The S RO, a utomatically, formulates a $\mathrm{n}$ opt imization p roblem and calls a genetic algorithm and direct search toolbox, as an optimization routine to solve the problem.

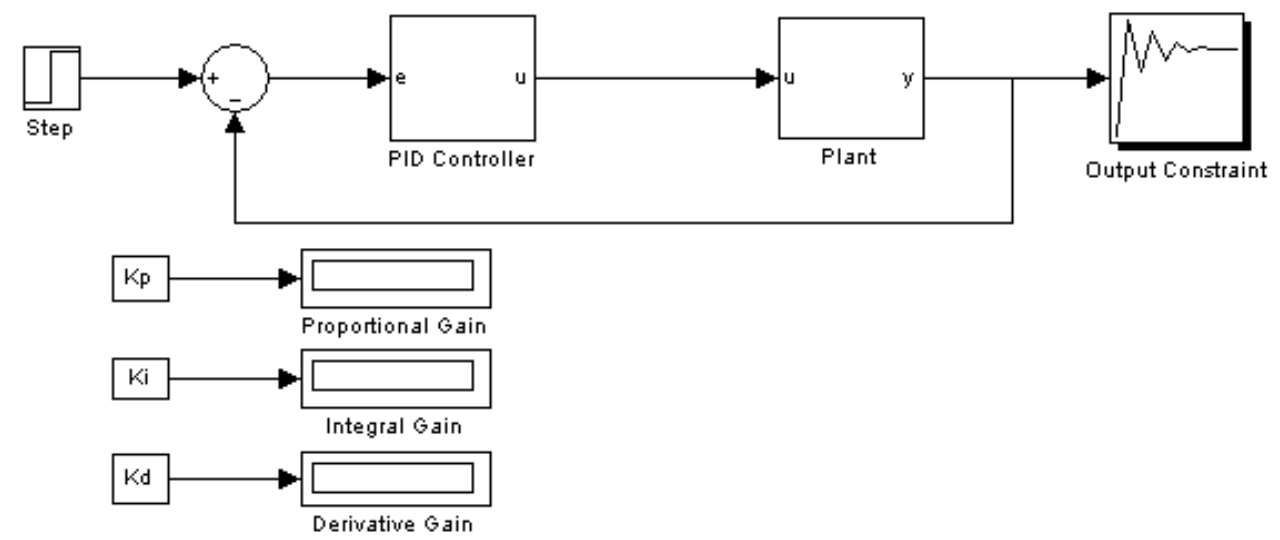

Fig. 2 Simulink Response Optimization (SRO) Toolbox

A classical discrete PID control system can be described as shown. The input-output relation of the PID controller is expressed mathematically by equation (1)[13].

$u(t)=K_{p} \cdot e(t)+T K_{i} \sum_{t=0}^{N} e(t)+K_{d} \frac{e(t)-e(t-1)}{T}$

where, $u(t)$ is the control s ignal, $e(t)$ is the e rror s ignal, a nd $K_{p}, K_{i}$, and $K_{d}$ denotes the proportional gain, integral gain and derivative gain respectively, $\mathrm{T}$ is the sampling time and $\mathrm{N}$ is the number of samples, $\mathrm{u}_{1}(\mathrm{t})$ represents the output of the controller at the sampling point $(\mathrm{t})$.

If the sampling period is short enough, the approximate calculation by equation (1) can get an accurate result and the discrete control process is close to the continuous control process. 
The digital PID Controller transfer function as a function of $\mathrm{z}$ has the following form [13]

$$
C(z)=K_{p}+K_{i} T\left(\frac{z}{z-1}\right)+\frac{K_{d}}{T}\left(\frac{z-1}{z}\right)
$$

where: $\mathrm{K}_{\mathrm{p}}, \mathrm{K}_{\mathrm{i}}$ and $\mathrm{K}_{\mathrm{d}}$ are the proportional, integral and derivative parameters of the controller respectively and ' $\mathrm{T}$ ' $\mathrm{t}$ he $\mathrm{s}$ ampling $\mathrm{t}$ ime. The $\mathrm{r}$ equired step response characteristics of $\mathrm{t}$ he engine are rise time $\left(t_{r}\right)=0.872 \mathrm{~s}$, settling time $\left(t_{s}\right)=4 \mathrm{~s}$ and maximum overshoot $\left(M_{p}\right)=2 \%$.

PID controller is t uned, based on the linearized ne ural model at di fferent ope rating poi nts, with $\mathrm{s}$ tep $\mathrm{c}$ hange f rom $41050 \mathrm{t}$ o $82000 \mathrm{r}$ pm. The opt imal P ID $\mathrm{p}$ arameters a re $\mathrm{s}$ hown i $\mathrm{n}$ Table (1) and the $r$ esulted s tep $r$ esponse s hown in Error! Reference source not found. represents the engine response at step input from $n=41050 \mathrm{rpm}$ to $n=82000 \mathrm{rpm}$. This input covers a wide range of engine speeds.

In contrast, if the same controller is us ed with an input of s maller a mplitudes as shown in Error! Reference source not found. and Error! Reference source not found., the response of the engine with the full range PID controller has a high over shoot response compared with the $\mathrm{s}$ cheduled P ID $\mathrm{c}$ ontroller. T his is due $\mathrm{t}$ o $t$ he $\mathrm{f}$ act $\mathrm{t}$ hat $\mathrm{t}$ he $\mathrm{P}$ ID controller is a 1 inear controller. It is thus not capable of de aling opt imally with a nonl inear constrained s ystem across its whole operating range.

Gain-scheduling P ID co ntrollers ar e pr oposed and their pa rameters a re $r$ ecalculated and shown in Table (1) using small-amplitude step inputs, to cover the engine operating ranges in which the data used for the estimation and validation are available.

Table (1) PID parameters at different step changes based on linearized neural network models and ARX model

\begin{tabular}{|c|c|c|c|c|c|}
\hline Model & $\begin{array}{l}\text { Step changes } \\
\text { (rpm) }\end{array}$ & $\mathbf{k}_{\mathbf{p}}$ & $\mathbf{k}_{\mathbf{i}}$ & $\mathbf{k}_{\mathbf{d}}$ & MSE \\
\hline \multirow{8}{*}{$\begin{array}{l}\text { Linearized neural } \\
\text { models at certain } \\
\text { design points }\end{array}$} & $41050-46050$ & 22.3465 & 11.7934 & 2.6964 & 0.002554 \\
\hline & $46050-51060$ & 9.5792 & 8.7627 & 0.99334 & 0.00336 \\
\hline & $51060-56050$ & 6.1426 & 8.6645 & 1.2238 & 0.00371 \\
\hline & $56050-61050$ & 6.3598 & 9.2752 & 1.1889 & 0.003231 \\
\hline & $61050-66060$ & 8.3136 & 12.1784 & 0.99342 & 0.002649 \\
\hline & $66060-71060$ & 5.1877 & 8.9899 & 1.6088 & 0.003409 \\
\hline & $71060-76100$ & 7.479 & 13.4361 & 1.3721 & 0.00245 \\
\hline & $76100-82000$ & 4.6472 & 10.6291 & 0.70902 & 0.002762 \\
\hline $\begin{array}{c}\text { Linearized model at } \\
n_{0}=61050 \mathrm{rpm}\end{array}$ & $41050-82000$ & 7.4465 & 11.5974 & 1.2223 & 0.02024 \\
\hline
\end{tabular}



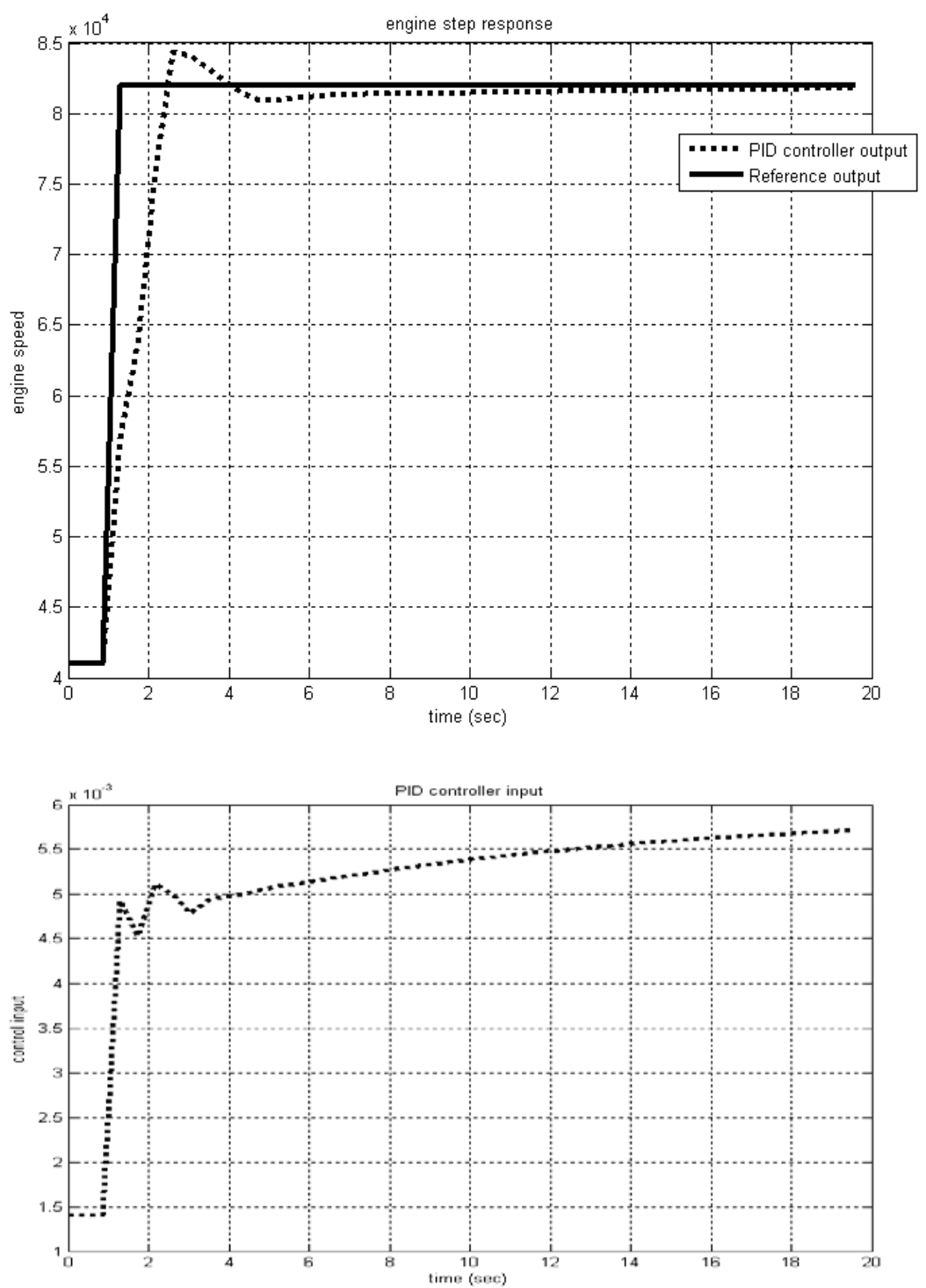

Fig. 3 Engine response with step change from $n=41050$ to $n=82000 \mathrm{rpm}$. (a) Engine step response, (b) PID controller input 

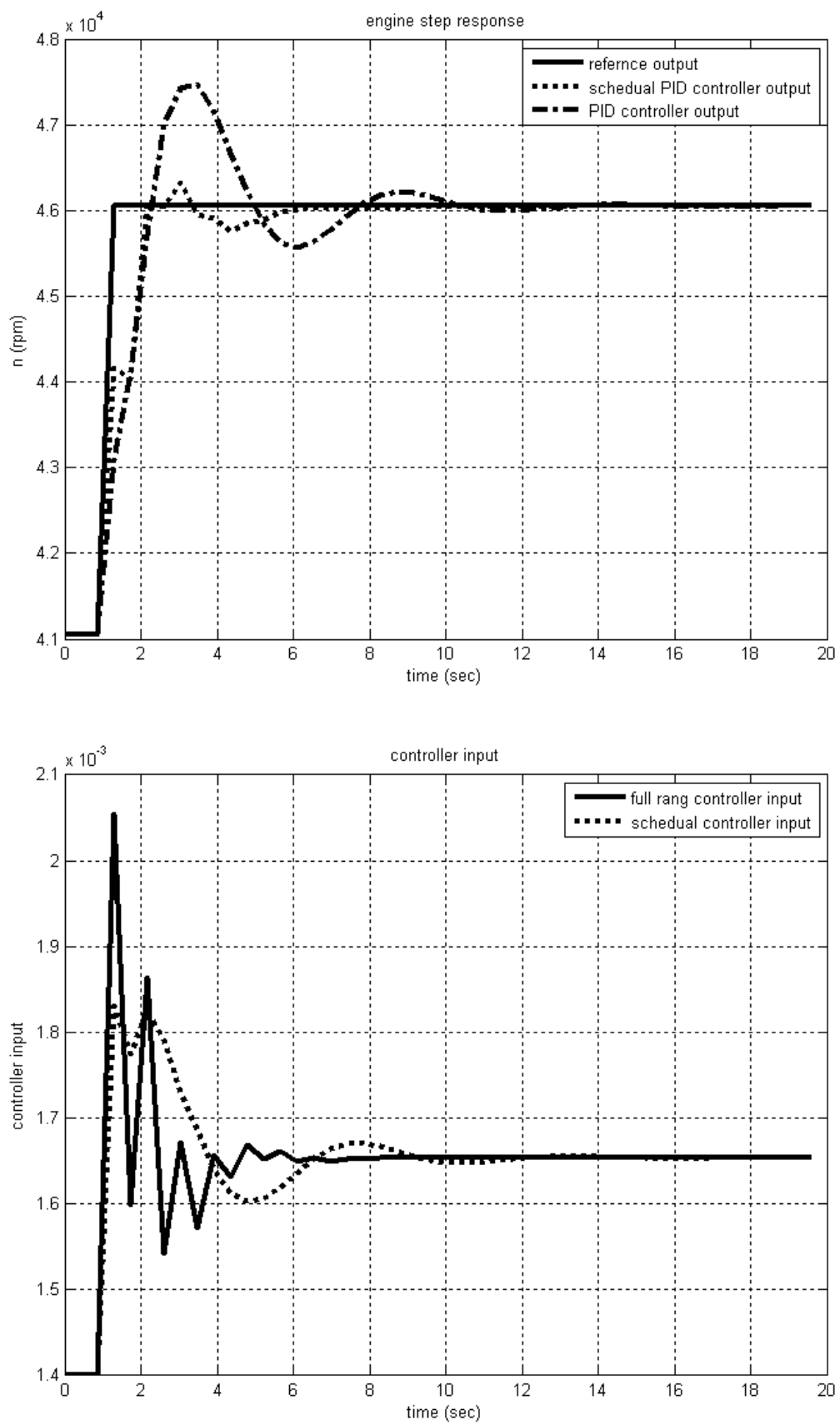

Fig. 4 Engine response with step change from $n=41050$ to $n=46050$ (a) Engine step response, (b) PID controller input 

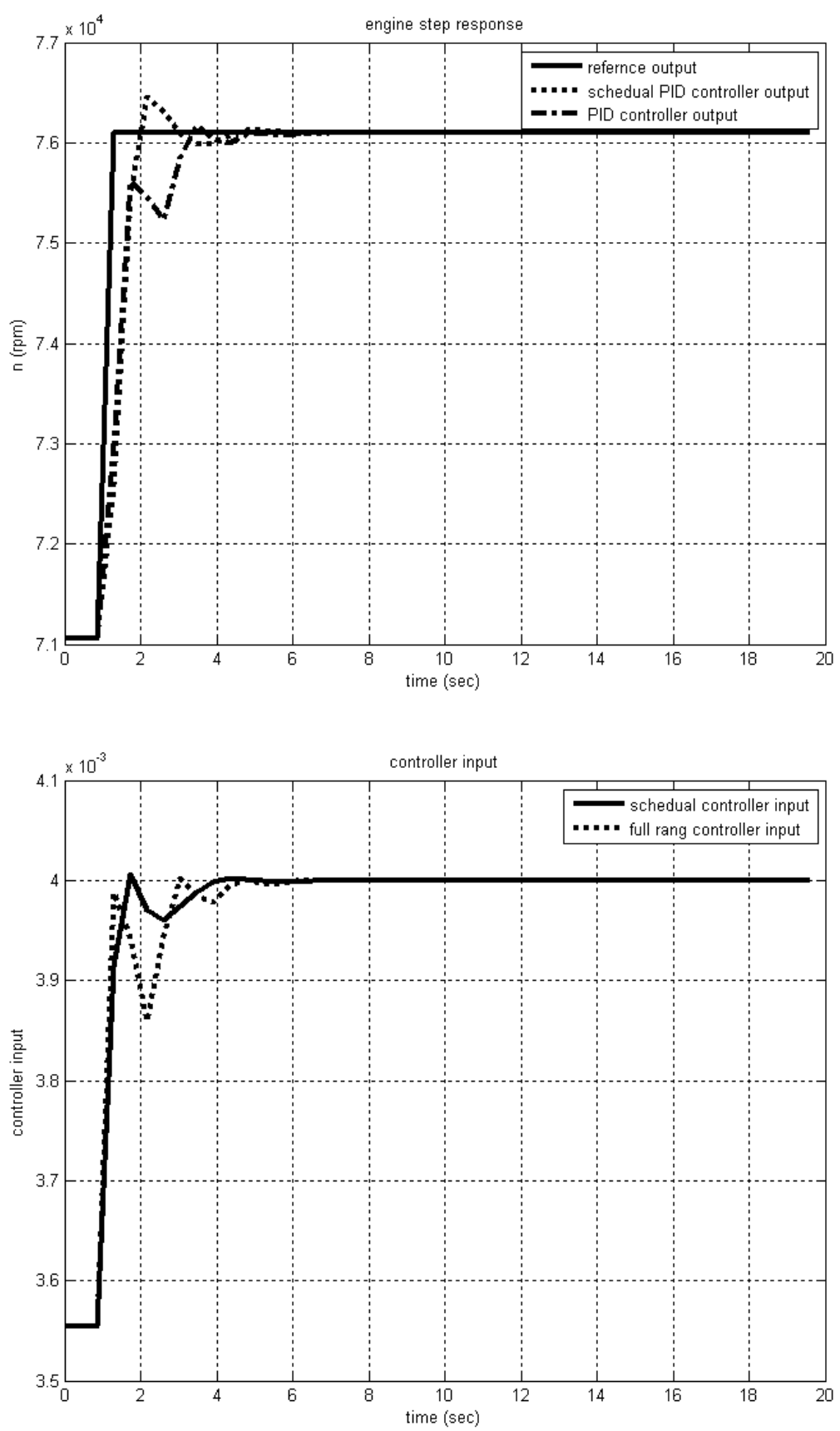

Fig. 5 Engine response with step change for $n=71060$ to $n=76100$ (a) Engine step response (b) PID controller input

Error! Reference source not found. represents the output from a neural model controlled with PID controller tuned at $n=61050 \mathrm{rpm}$, the curve shows that the engine response became better as engine speed became near to the $n_{0}=61050 \mathrm{rpm}$ and the error increased as the point became far away from the design point $n_{0}$. 

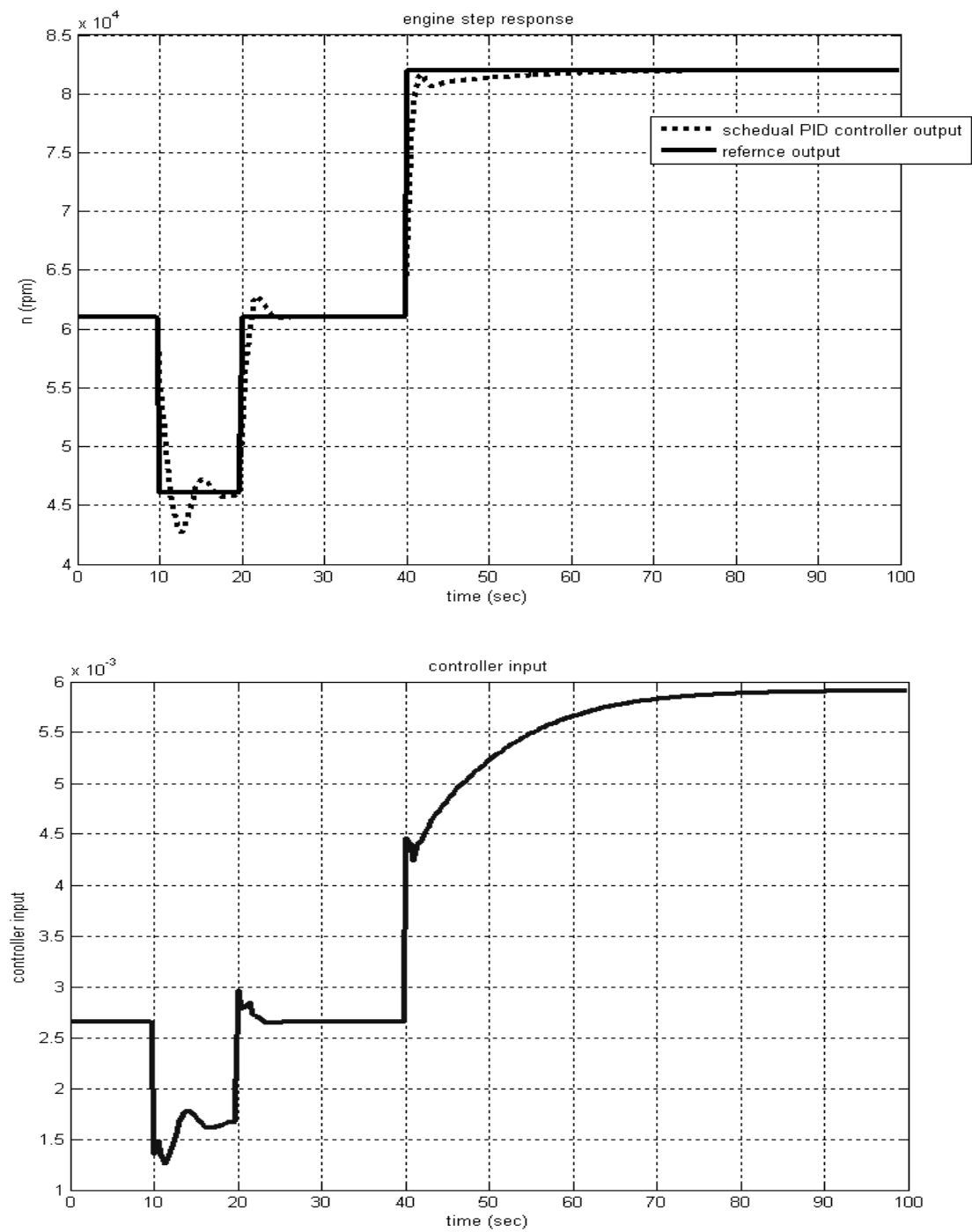

Fig. 6 Engine response with different steps change from $n=61050$ to $n=82000$ (a) Engine step response (b) PID controller input

The system nonl inearity is well illus trated if an increasing a mplitude square pul se signal is given to the system. Error! Reference source not found. shows the response of the engine in case of square pulse signal input with the PID controller. There is an over shoot in the engine response. 


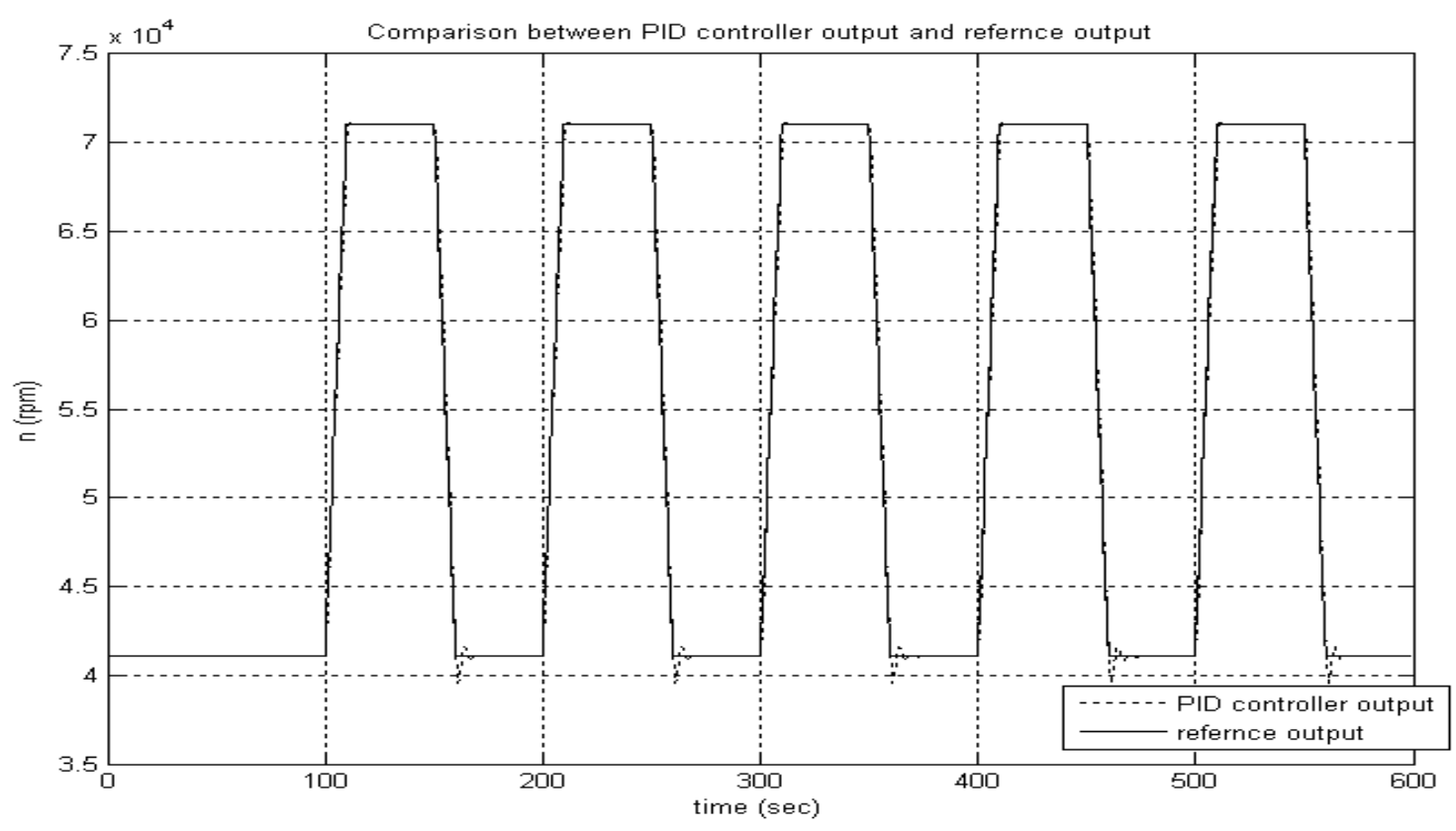

Fig. 7 The response of the engine in case of square pulse signal input with the PID controller

\section{Predictive controller design}

In order to implement the predictive controller strategy, the basic structure shown in Error! Reference source not found. is used. A model is us ed to predict the future plant outputs, based on pa st and current values and on the proposed opt imal future control actions. These actions are calculated by the optimizer taking into account the cost function (where the future tracking error is considered) as well as the constraints.

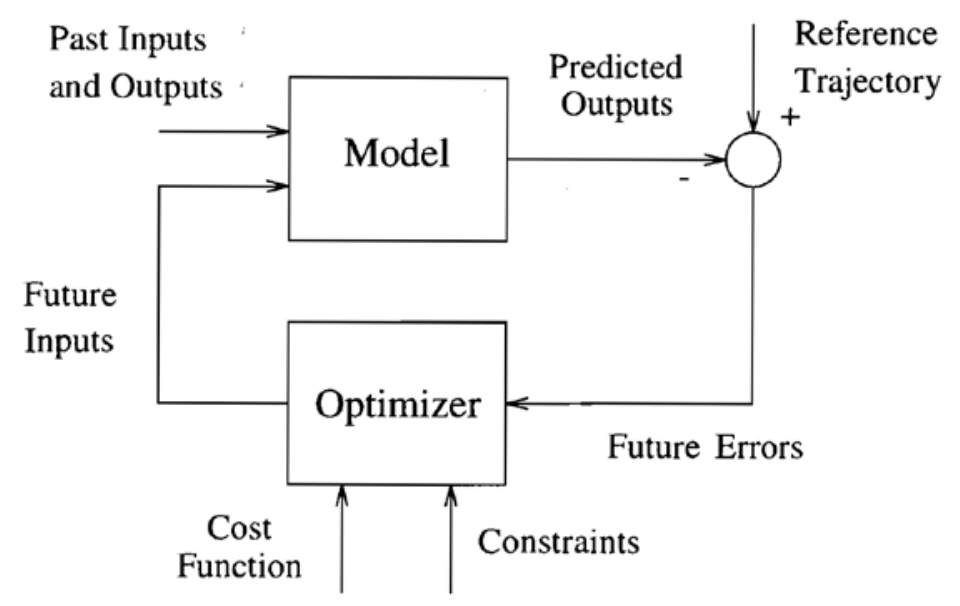

Fig. 8. Basic structure of MPC

The basic idea of GPC is to calculate a sequence of future control signals in such a way that it minimizes a mul tistage cost function defined o ver a $p$ rediction hor izon. The i ndex to be optimized is the ex pectation of a qua dratic function measuring the di stance be tween the predicted $\mathrm{s}$ ystem out put a nd $\mathrm{s}$ ome $\mathrm{p}$ redicted $\mathrm{r}$ eference $\mathrm{s}$ equence ov er $\mathrm{t}$ he hor izon $\mathrm{pl} u \mathrm{u}$ a quadratic function m easuring the control e ffort. G PC provides a $\mathrm{n}$ e xplicit s olution (in the absence of $\mathrm{c}$ onstraints), i t $\mathrm{c}$ an $\mathrm{d}$ eal with uns table a nd no $\mathrm{m}$ inimum pha se $\mathrm{pl}$ ants a nd incorporates the c oncept of $\mathrm{c}$ ontrol ho rizon a $\mathrm{s} \mathrm{w}$ ell a $\mathrm{s} t$ he consideration of $\mathrm{w}$ eighting of 
control increments in the cost function. The general set of choices available for GPC leads to a greater variety of control obj ectives compared to other approaches, some of which can be considered as subsets or limiting cases of GPC.

The GPC algorithm consists of applying a control sequence that minimizes a multistage cost function $J$ :

$$
J=\sum_{j=N_{1}}^{N_{2}}[\hat{y}(k+j)-w(k+j)]^{2}+\lambda \sum_{j=1}^{N_{u}} \Delta u(k+j-1)^{2}
$$

Subject to: $\Delta u(k+j-1)=0$ for $N_{u}<j<N_{2}$, where $\mathrm{N}_{1}$ denotes the minimum prediction horizon, $\mathrm{N}_{2}$ the maximum prediction horizon and $\mathrm{N}_{\mathrm{u}}$ the control horizon, $\lambda$ is a w eight factor penalizing $\mathrm{c}$ hanges in the control input to ob tain s mooth control input signals and $\mathrm{d}$ is the system time delay.

Then the predictor equation becomes in matrix form

$$
\hat{\mathbf{y}}=\mathbf{G} \cdot \tilde{\mathbf{u}}+\mathbf{f}
$$

where:

$$
\begin{aligned}
& \hat{\mathbf{y}}=\left[\begin{array}{llll}
\hat{y}\left(k+N_{1}\right) & \hat{y}\left(k+N_{1}+1\right) \quad \cdots & \hat{y}\left(k+N_{2}\right)
\end{array}\right]^{T} \\
& \mathbf{G}=\left[\begin{array}{ccccccc}
g_{N_{1}} & g_{N_{1}-1} & \cdots & g_{1} & 0 & \cdots & 0 \\
g_{N_{1}+1} & \ddots & & & \ddots & \ddots & \vdots \\
\vdots & & \ddots & & & g_{1} & 0 \\
\vdots & & & \ddots & & & g_{1} \\
g_{N_{2}} & g_{N_{2}-1} & & & \ddots & & g_{N_{2}-N_{u}+1}
\end{array}\right] \\
& \tilde{\mathbf{u}}=\left[\begin{array}{llll}
\Delta u(k) & \Delta u(k+1) & \cdots & \Delta u\left(k+N_{u}-1\right)
\end{array}\right]^{T} \\
& \mathbf{f}=\left[\begin{array}{lll}
f\left(k+N_{1}\right) & \cdots & f\left(k+N_{2}\right)
\end{array}\right]^{T}
\end{aligned}
$$

Then $J$ could be written in matrix form as:

$$
J=(\hat{\mathbf{y}}-\mathbf{w})^{T} \cdot(\hat{\mathbf{y}}-\mathbf{w})+\lambda \tilde{\mathbf{u}}^{\mathbf{T}} \cdot \tilde{\mathbf{u}}
$$

where:

$$
\mathbf{w}=\left[\begin{array}{lll}
w\left(k+N_{1}\right) & \cdots & w\left(k+N_{2}\right)
\end{array}\right]^{T}
$$

Minimize $J$ to get optimum $\tilde{\mathbf{u}}$ we get:

$$
\tilde{\mathbf{u}}^{*}=\left(\mathbf{G}^{T} \cdot \mathbf{G}+\lambda \mathbf{I}\right)^{-1} \cdot \mathbf{G}^{T} \cdot(\mathbf{w}-\mathbf{f})
$$

Taking the first element of the control sequence (as the receding horizon principle)

$$
\Delta u^{*}(k)=\mathbf{H} \cdot(\mathbf{w}-\mathbf{f})
$$

where:

$$
\mathbf{H}=\left[\begin{array}{lllll}
1 & 0 & 0 & \cdots & 0
\end{array}\right]^{T}\left(\mathbf{G}^{T} \cdot \mathbf{G}+\lambda \mathbf{I}\right)^{-1} \cdot \mathbf{G}^{T}
$$


For a linear time-invariant system the parameter $\mathbf{H}$ is unchanged over the time. But the free response $f$ should be calculated every time step.

The incremental controller ensures zero offsets even with non-zero constant disturbance. The choices of $\mathrm{p}$ arameters $\left(N_{1}, N_{2}, N_{u}\right.$ and $\left.\lambda\right)$ de termine the s tability and performance of the GPC controller. Some guidelines for selecting them exist in [6-10].

\section{Free System Response ( $\mathrm{f}$ )}

To get the free system response the prescribed NN is given a zero increment vector $\hat{\tilde{\mathbf{u}}}$ then the output predicted vector $\hat{\mathbf{Y}}$ will be the system free responsef .

\section{Impulse system response ( $G$ )}

The impulse response of the system is calculated using trained NN model with a linearization around the current operating point. To get the first column of the $\mathrm{G}$ matrix a small value for $\Delta \hat{u}_{k+1}$ is as sumed as small value $\varepsilon$, where $\varepsilon \ll 1$ and the corresponding out put prediction is obtained.

$\hat{\tilde{\mathbf{u}}}=\left[\begin{array}{llll}\varepsilon & 0 & 0 & 0\end{array}\right]$

Then the first column will be

$\mathbf{G}_{(1)}=\frac{1}{\varepsilon} \cdot(\hat{\mathbf{Y}}-\mathbf{f})$

It will be easy after that to form the special shape of $\mathbf{G}$ matrix then calculate $\mathbf{H}$ vector.

\section{Predictive controller scheme}

The proposed c ontrol s cheme Error! Reference source not found. consists of a nonl inear neural $\mathrm{n}$ etwork m odel in the form of $\mathrm{N} \mathrm{N}$ m odel and a l inear G PC c ontroller. The $\mathrm{n}$ eural model is trained of f-line $w$ ithin the c omplete $r$ ange of $s$ ystem input. After pe rforming the training, the $\mathrm{n}$ etwork is then us ed by the G PC controller to calculate the free response of nonlinear s ystem e very time s tep. Every batch of time the impul se response ma trix is calculated through linearization.

The control law Error! Reference source not found. is computed every time-step to get the next control increment.

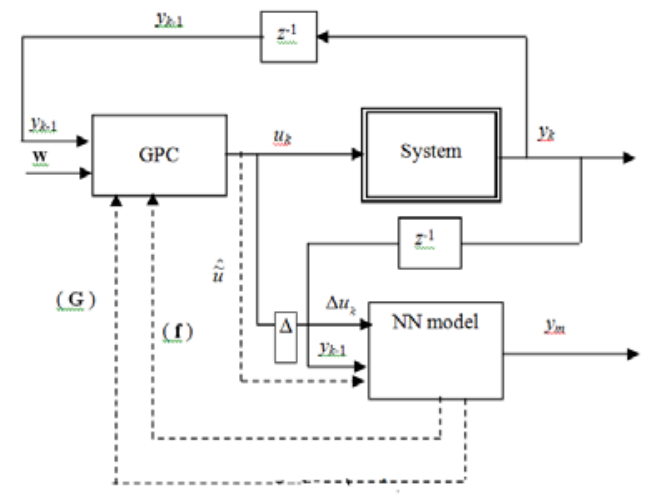

Fig. 9 Proposed Neural Network GPC Control Scheme

\section{Application to the SR-30 NN model}

The predictive controller parameters are $N_{1}=1, N_{2}=4, N_{u}=1, \lambda=0.05$ 
The system nonl inearity is w ell illus trated if an increasing am plitude square pul se signal is given to the system. The Simulations results and Comparison with the PID controller with the same input will be illustrated below.

Error! Reference source not found. shows the response of the engine in case of enhancing the full-step response from 41050 t o $82000 \mathrm{r} \mathrm{pm}$. It is clear that the os cillation a round final position eliminated and the rise and settling time are reduced
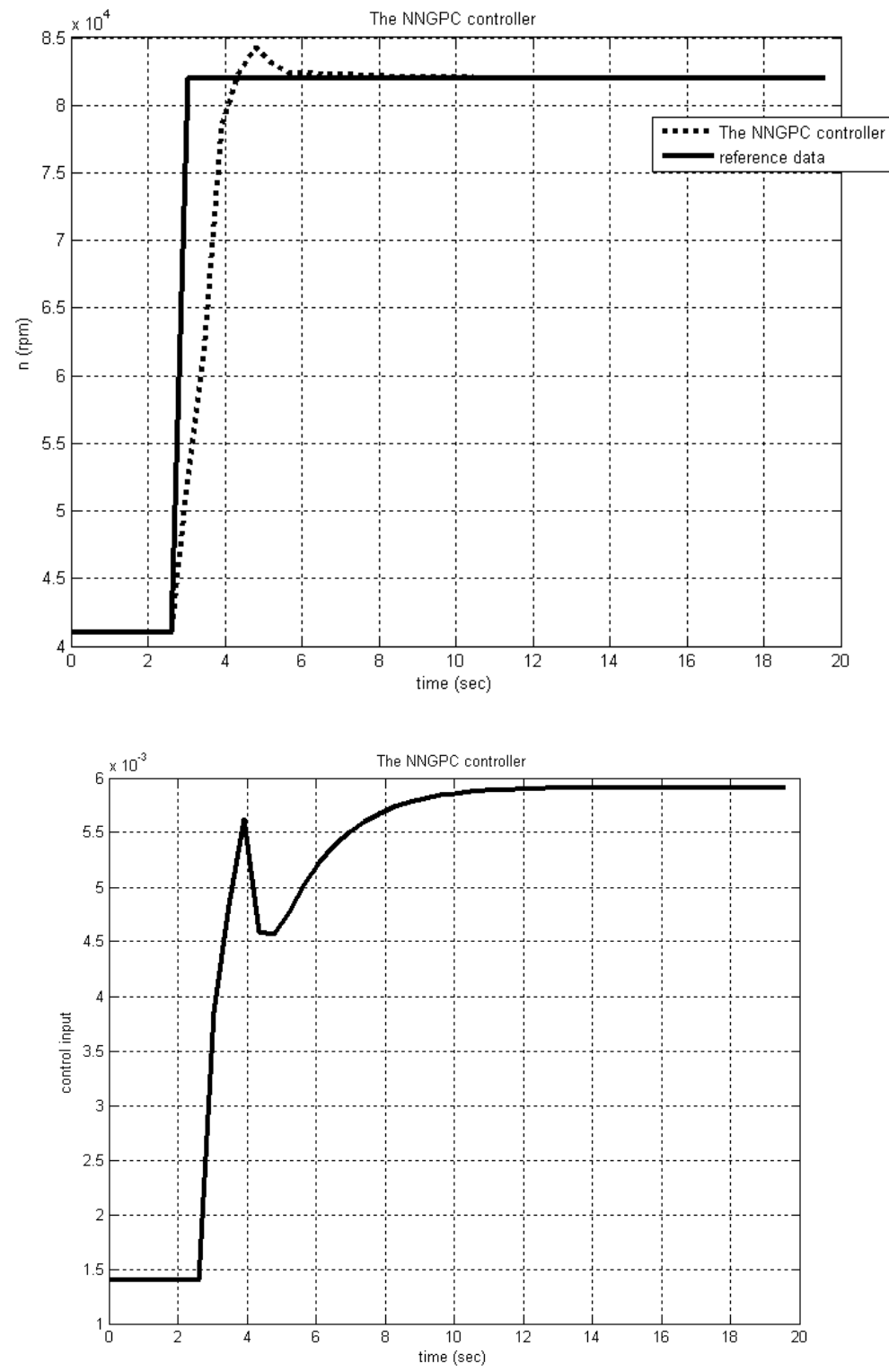

Fig. 10 Engine response with step change from 41050 to $82000 \mathrm{rpm}$ (a) engine step response, (b) predictive controller input

Error! Reference source not found. shows the engine step response with random step input from 61050 to 46050 finally to $82000 \mathrm{rpm}$. It is clear that the engine response with predictive controller is improved where the oscillations are reduced and the settling time is reduced. 

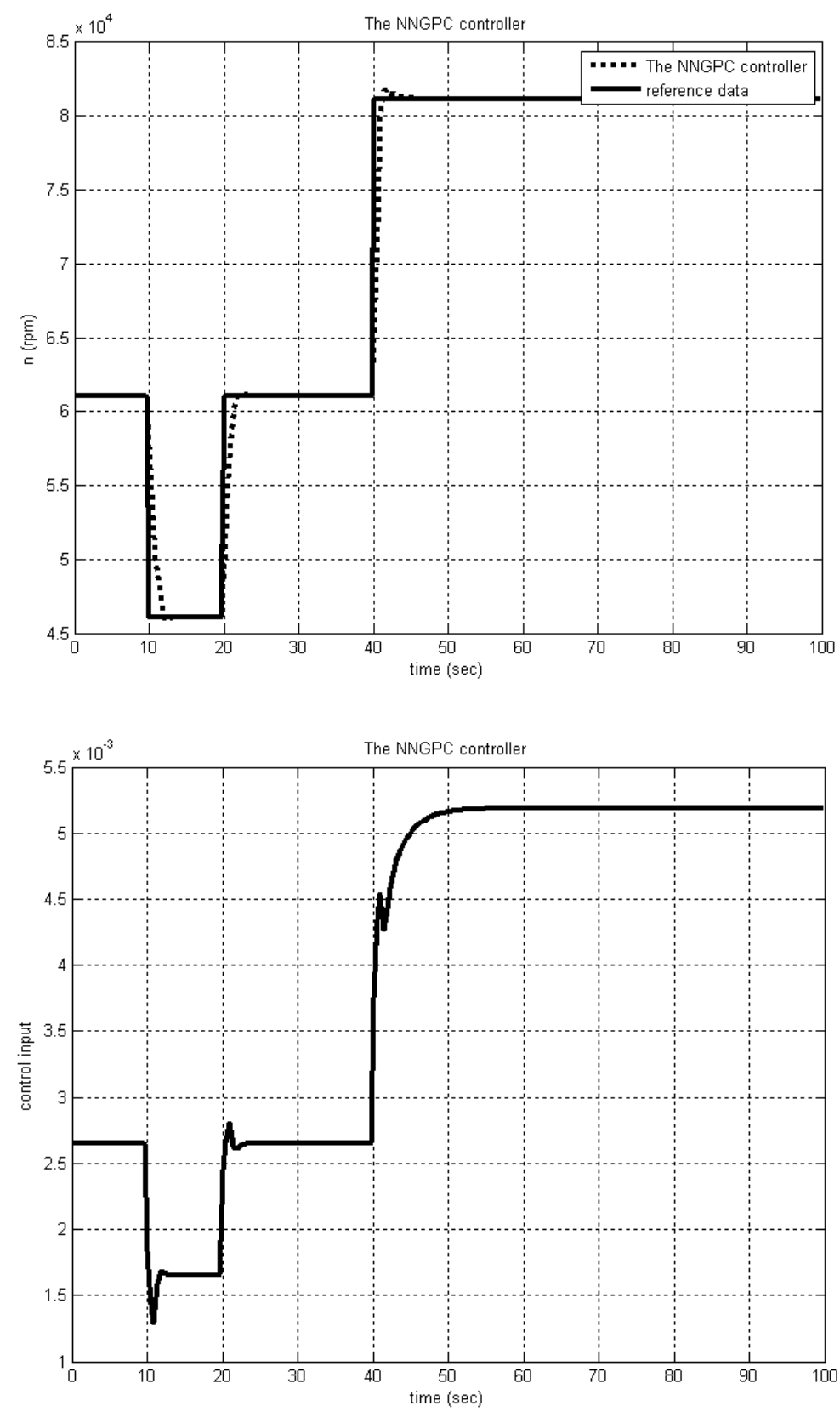

Fig. 11 Engine response with different steps change from $n=61050$ to $n=82000$ (a) engine step response, (b) predictive controller input

The system nonl inearly is w ell illus trated if an increasing amplitude s quare pul se signal is given to the system. Error! Reference source not found. the response of the engine in case of square pulse signal input with the predictive controller. It is clear that there is no over shoot in the engine response. 

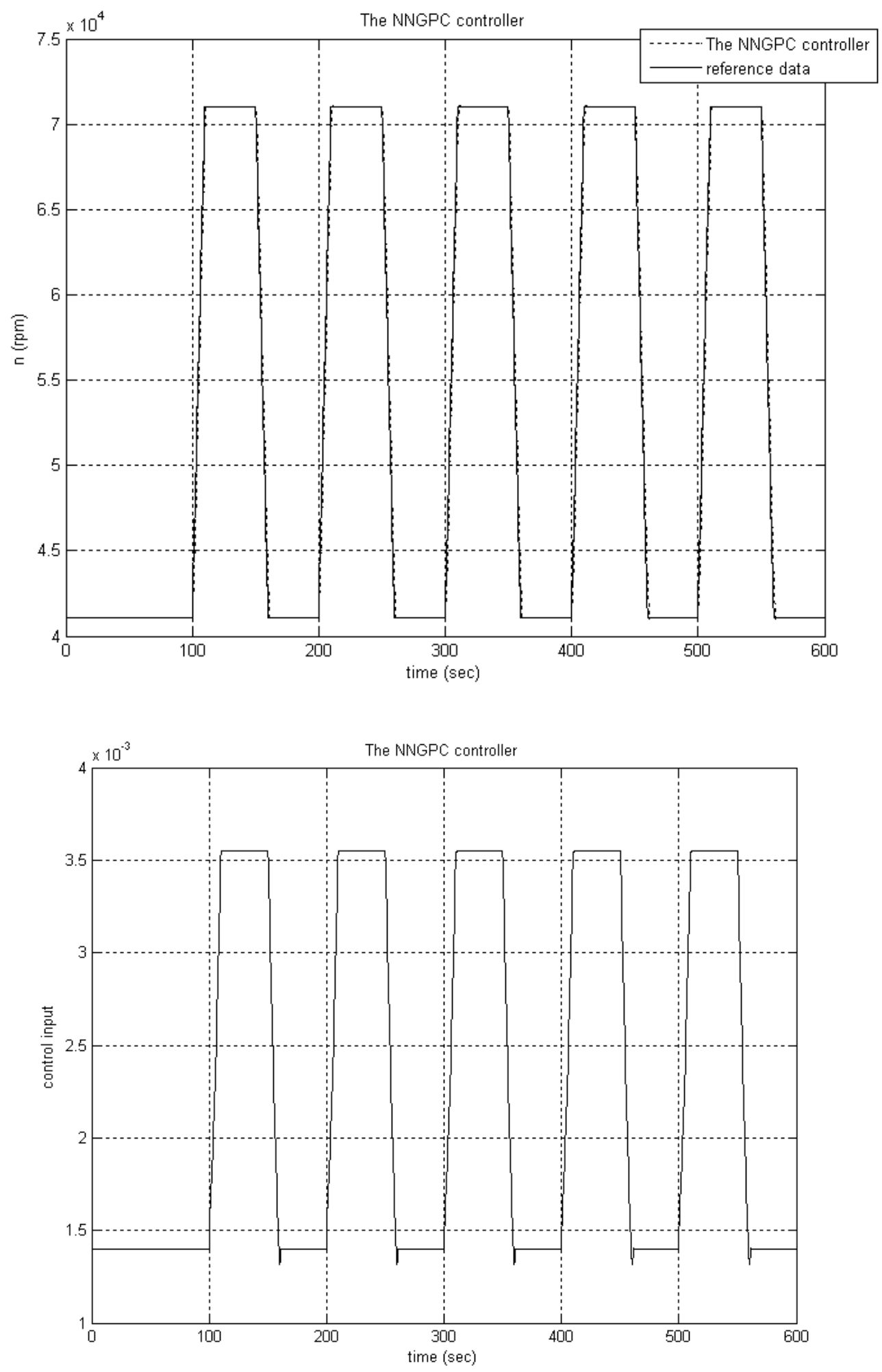

Fig. 12 Engine response in case of square pulse signal input (a) engine step response, (b) predictive controller input

Results of comparison between PID controller and predictive controller In $\mathrm{t}$ his s ection, a comparison i s $m$ ade $b$ etween $t$ he $P$ ID $c$ ontrollers with $t$ he pr edictive controller with respect to the same input signal as shown in Error! Reference source not found., 14 and 15 . 

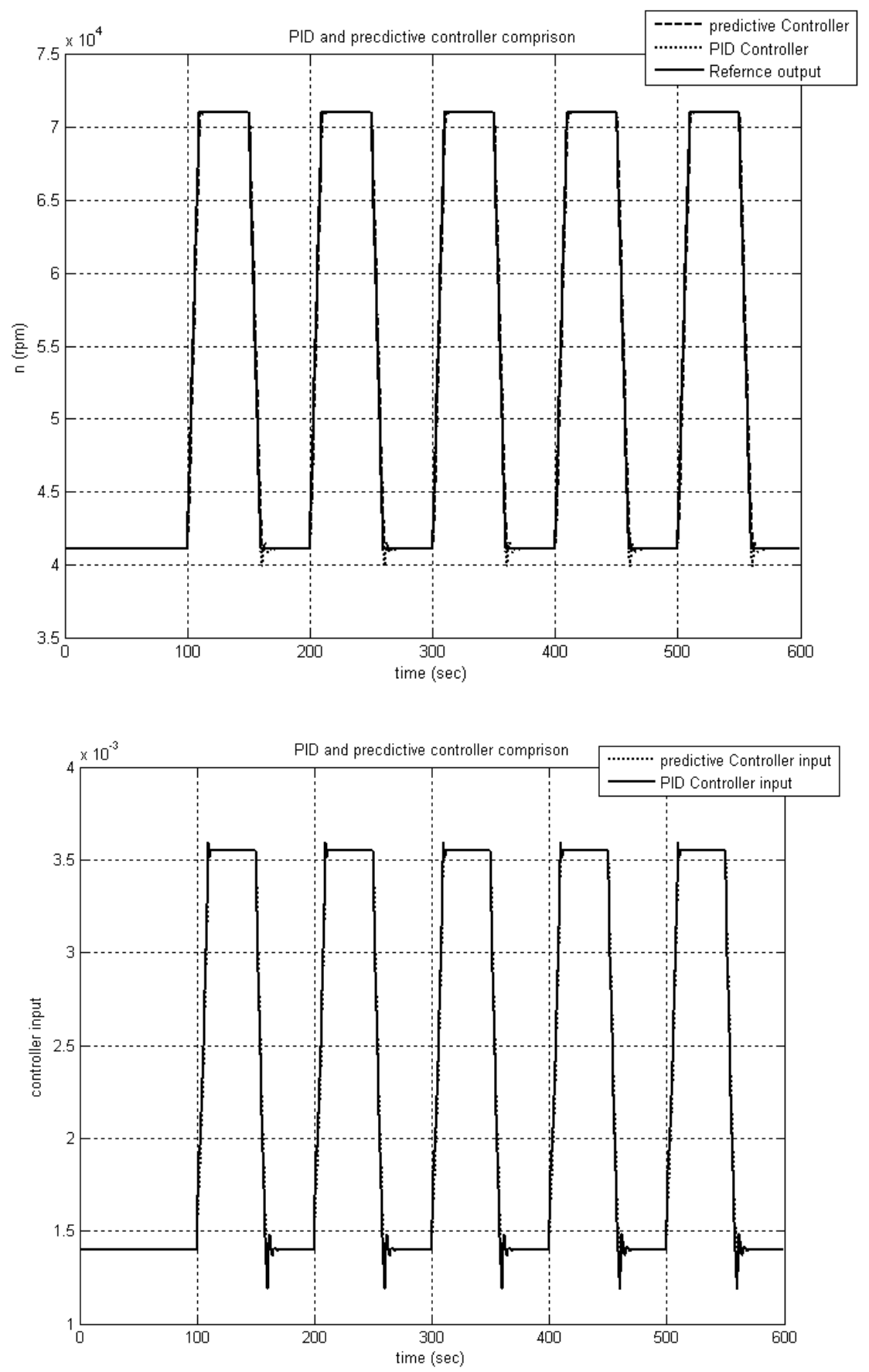

Fig. 13 Comparison between PID and predictive controllers in case of in case of square pulse signal input (a) engine step response, (b) controller input 

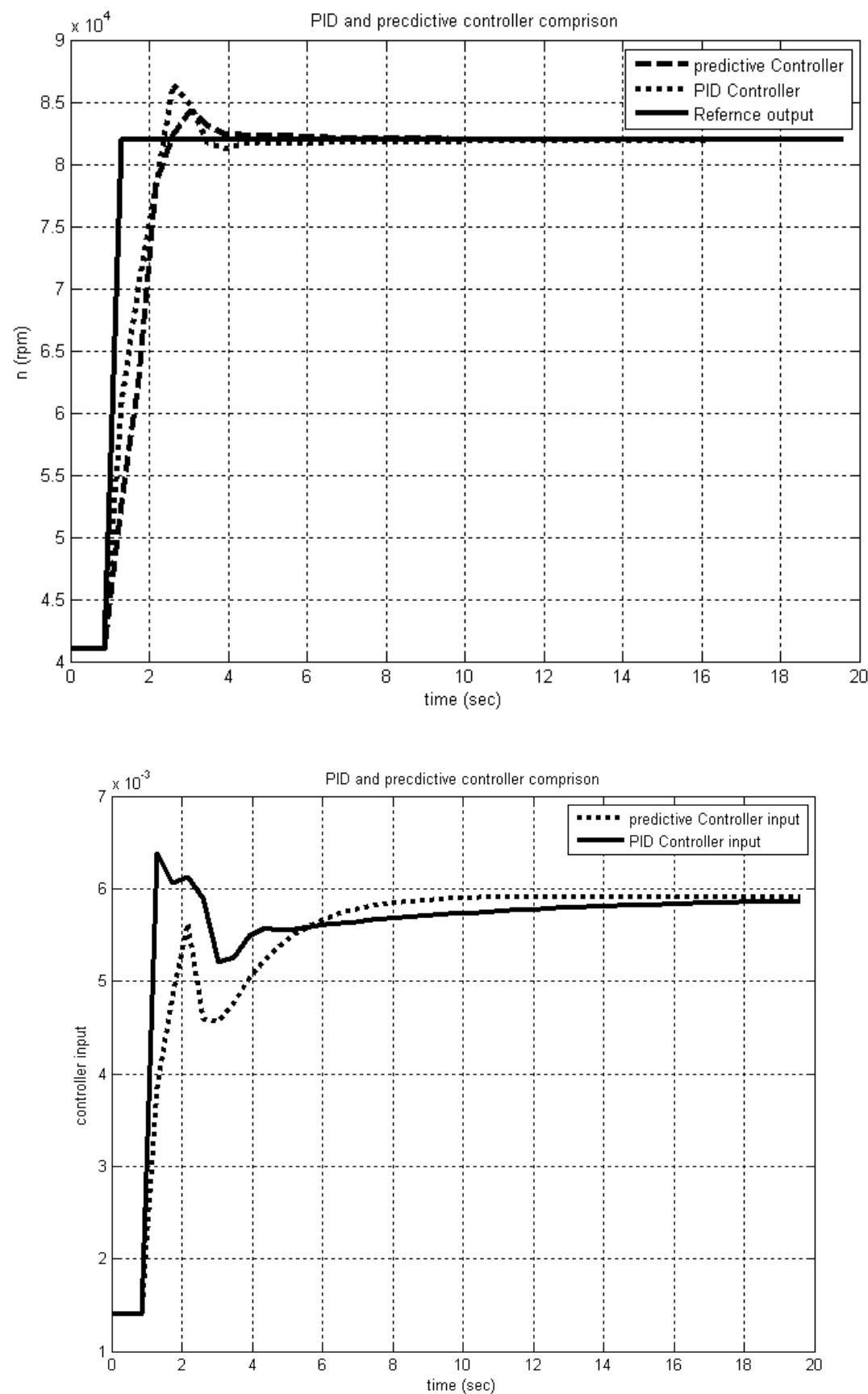

Fig. 14 Comparison between PID and predictive controllers in case of step input from 41050 to 82000 rpm (a) engine step response, (b) controller input 

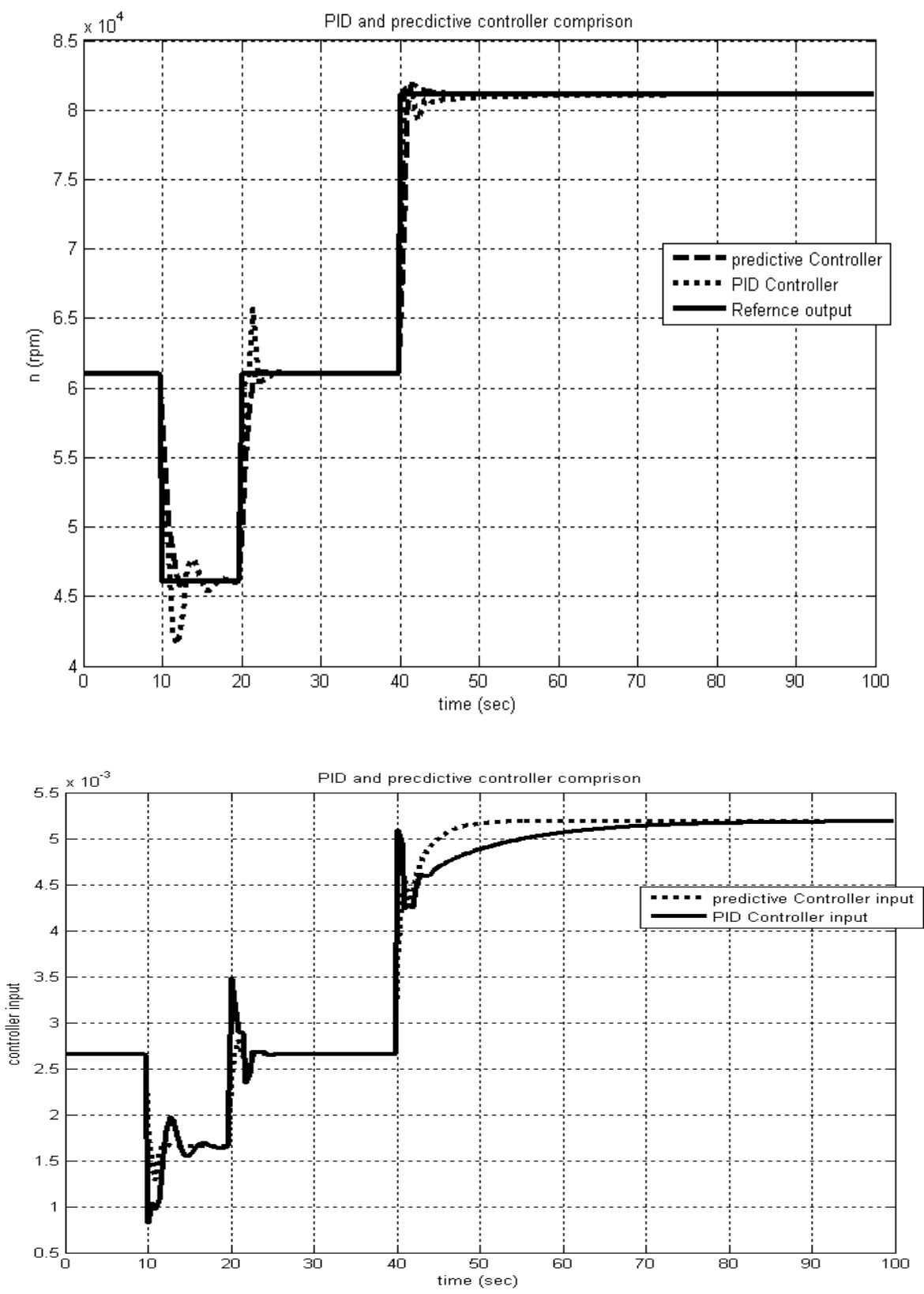

Fig. 15 Comparison between PID and predictive controllers in case of different steps input from 61050 to $82000 \mathrm{rpm}$ (a) engine step response, (b) controller input

The Simulations results of the predictive controller and Comparison with the P ID controller with the same input are illustrated above which show that the engine performance is improved with $t$ he pr edictive controller, $t$ he $r$ esponse os cillation a nd ove rshoot is s maller $w$ ith $t$ he predictive controller rather than the PID controller, the engine rise time is also smaller. It can be therefore con cluded that the parameters in the gain-scheduling P ID c ontroller need to be changed with the operating range, but using predictive controller enables a global controller to be i mplemented a nd provides the opt imal c ontrol pe rformance a cross the ope rating $r$ ange. Predictive c ontroller provides the be st c ontrol performance against di sturbances and model uncertainties. 


\section{Conclusion}

A representative neural network SR-30 engine model was us ed to develop a P ID controller and pr edictive controller. $R$ esults from the $t$ wo c ontrollers $w$ ere compared a nd p redictive controller found to be accurate for engine control during the full operating rang.

The following results are derived from our analysis:

1. PID controller was built based on the neural networks model of the SR-30 engine.

2. Tuning of the P ID $c$ ontroller $w$ as pe rformed $w$ ith of fline $w$ ith a $g$ enetic opt imization technique.

3. PID $\mathrm{c}$ ontroller $\mathrm{c}$ annot $\mathrm{c}$ ope $\mathrm{w}$ ith m odel $\mathrm{c}$ hanges $\mathrm{i} \mathrm{n} \mathrm{t}$ he $\mathrm{w}$ hole ope rating $\mathrm{r}$ ange of $\mathrm{t}$ he engine.

4. A ne ural m odel $\mathrm{w}$ as us ed as a pr edictor f or the cal culation of G PC pa rameters. The nonlinear $\mathrm{s}$ ystem free $\mathrm{r}$ esponse $\mathrm{w}$ as obt ained $\mathrm{b}$ y $\mathrm{r}$ ecursive future pr edictions $\mathrm{w}$ hile the dynamic response matrix was obtained by instantaneous linearization of the input /output relation.

As a conclusion, the results illus trate clearly the improvements in system performance that could be achi eved with a ne ural predicative con troller com pared to that of a classical P ID controller.

\section{References}

[1] Garcia C.E., P rett D .M. , a nd M.M orari,“ Model predictive control: theory and practice- a survey," Automatica, 25(3): 335-348, (1989).

[2] D.W. Clarke, C Mohtadi, and P.S. Tuffs. "Generalized Predictive Control. Part I. The Basic Algorithm. Automatica" 23(2):137-148, 1987.

[3] D.W. C larke a nd P .J. G awthrop. "Self-tuning Control. Proceedings" IEEE, 123: 633640,1979.

[4] A. M . B ayoumy, J . B ordeneuve-Guibé, "A Neural Predictive Control Scheme For Nonlinear Plants", D epartment of A vionics a nd S ystems, E NSICA, T oulouse, FRANCE, AIAA 2002-1541.

[5] I. M. Atia and A. M. Bayoumy "Testing and Model Identification of a Turbojet Engine Using Neural Networks". ASAT-14, 2011

[6] Clarke D .W., C . M ohtadi a nd P .S. T uffs,“ Generalized Predictive Control. Part2: Extensions and interpretations,” Automatica, vol.23, №2, pp. 149-160, (1987)

[7] Watanabe, A., 1 men, S. M., Leland, R., W hitaker, K. W ., and T revino, L. C., 2004, "Soft Computing Applications on SR-30 Turbojet Engine" AIAA Paper No. 2004-6444.

[8] Andoga, Rudolf, Ladislav Madarasz, and Ladislav Fozo. "Digital Electronic Control of a Small Turbojet Engine - MPM 2." 12. International Conference on Intelligent Engineering Systems. Miami, Florida. 37-40, 2008.

[9] Michael Lichtsinder, Yeshayahou Levy "Jet Engine Model for Control and Real-Time Simulations" Journal of E ngineering for G as T urbines a nd P ower, 2006 b y ASME, OCTOBER 2006, Vol. 128 / 745.

[10] Clarke D .W. a nd C . M ohtadi "“ Properties of generalized predictive control" Proceedings of the 10t h triennial w orld c ongress of IFAC, M unich, FRG, pp. $65-76$, (1987).

[11] Clarke D.W. and R. Scattolini, “ Constrained receding-horizon predictive control” IEEE proceedings-D, vol.138, No4, pp.347-354, (1991)

[12] Rawlings J . B . a nd M uske K . R .," The stability of constrained receding horizon control" IEEE Trans. Automatic control, 38(10):1512 - 1516, (1993)

[13] Charles L Phillips, "Digital control system analysis and design". 